\title{
Ethics and law
}

\section{Emerging inequality and potential unconstitutionality - the case for reform of the intern priority system}

\section{Dev A S Kevat \\ LLB(Hons), MPH \\ PhD Candidate \\ Fiona J Lander MB BS(Hons), LLB(Hons),
Doctor $^{2}$}

1School of Public Health Monash University, Melbourne, VIC

2 Austin Hospital Melbourne, VIC

dev.kevat@monash.edu

doi: 10.5694/mjal2.10967 nternship, the gateway from the primary medical degree to further medical training in Australia, is becoming increasingly competitive. We question the fairness and legality of the "priority system", in which states give preference to Australian students graduating from medical schools in their state over all other applicants, including interstate Australian graduates, who form part of lower priority groups (Box 1 and Box 2). The implications of this system for international graduates have been considered ${ }^{7}$ and, irrespective of ethical and policy reasons for offering international students internships, we agree with the conclusion that the legal position of international students is weak. The impact of the priority system on interstate applicants has not been addressed.

Previously, interstate movement of medical graduates at internship level was feasible due to a national shortage of medical graduates. However, the increasing scarcity of positions has made such movement much more challenging, and has caused friction between some jurisdictions. This was illustrated by the recent removal of Australian Capital Territory hospitals from the New South Wales priority system, with ACT graduates now considered to be interstate applicants in NSW. ${ }^{8}$ The priority system, while administratively convenient, is inequitable, potentially unconstitutional, and inconsistent with medical school selection policies and recent registration changes facilitating free movement of medical professionals nationwide.

The priority system generally means that even the most meritorious interstate candidates cannot be selected for internship positions until the least meritorious "local" candidate is selected. This system has a negative impact on a proportion of the $27 \%$ of Australian medical students who complete their medical degree outside their home state and wish to return due to strong personal or professional links (Mary Solomon, Executive Officer, Medical Deans Australia New Zealand, personal communication, 13 March 2012). Such profound "handicapping" does not occur at postgraduate year (PGY) 2 or 3 levels. However, graduate movement at these levels will become more difficult. Internal candidates have the advantage of known referees and an established relationship, and in some states, such as NSW, interns generally fill PGY2 positions due to extended contracts. Given the forecast bottleneck of a 400-place shortfall in first-year training positions within 4 years, ${ }^{9-11}$ securing an internship in the state in which individuals wish to train long-term will become more critical.

As recent growth in graduate numbers has not been proportional to population size, ${ }^{12}$ applicants in more com-

\section{Summary \\ - Internship selection is becoming more competitive due to substantial increases in numbers of medical graduates. \\ - Australian states operate a "priority system" for medical internship selection which discriminates against Australian interstate applicants. \\ - This discrimination arguably infringes section 117 of the Australian Constitution, which seeks to ensure that all citizens are treated equally and promotes national unity. \\ - The priority system should be reformed. It is inequitable and inconsistent with other aspects of medical training and regulation.}

petitive states may receive job offers from lower-preferenced hospitals than applicants of equivalent merit in other states. It would be advantageous for a candidate keen on competitive or rarer specialties, such as cardiothoracic surgery or pathology, to gain employment at a less competitive interstate hospital offering such rotations. There is a policy advantage in facilitating exposure of interested graduates to rotations as soon as possible, particularly in specialties which have a workforce shortage. ${ }^{13}$ References from rotation supervisors are important in the selection process for many training programs, ${ }^{14,15}$ but these possibilities are greatly restricted within the current priority system. Furthermore, some states do not place domestic full-fee students in their highest (sub)category and guarantee them an internship (Box 3); these students are then further disadvantaged if they seek an internship interstate.

Noting that medical schools and colleges do not discriminate on the basis of state of residence in their selection of students and trainees, the best principle to use is that all Australian graduates should be able to apply to any hospital that best meets their career aspirations, and no citizen should be advantaged over another simply by virtue of residential location. The priority system may infringe a clause of the Australian constitution which enshrines this principle and prohibits such discrimination.

\section{Is the priority system unconstitutional?}

Section 117 of the Commonwealth of Australia Constitution Act 1900 (Cwlth) seeks to strengthen the nation's federal structure through prevention of state protectionism:

A subject of the Queen, resident in any state, shall not be subject in any other state to any disability or discrimination 


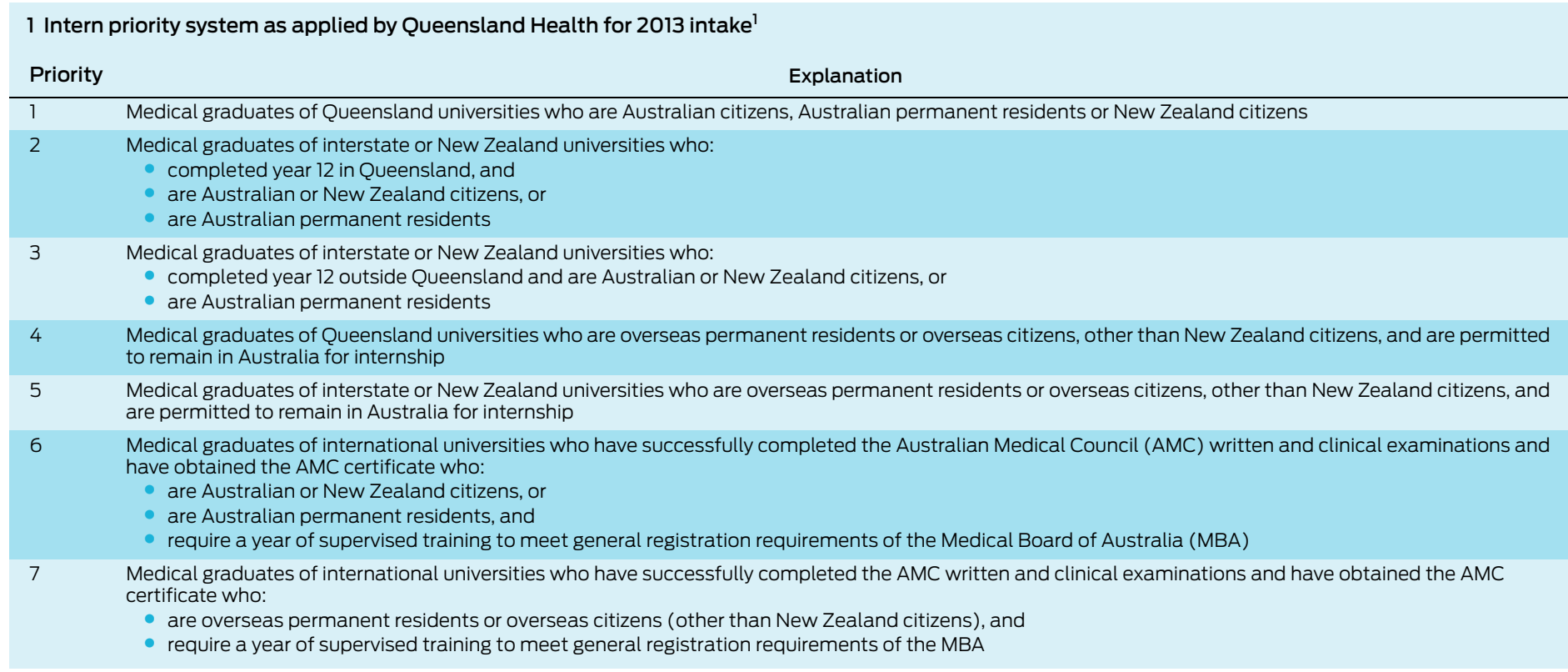

which would not be equally applicable to him if he were a subject of the Queen resident in such other state.

This section could operate to prevent, for example, an applicant for internship in Queensland who was trained in Tasmania from being treated differently to a candidate trained and residing in Queensland.

\section{The Street case}

Section 117 was considered by the High Court of Australia in the key case of Street $v$ Queensland Bar Association, concerning the admission rules to become a barrister in Queensland. ${ }^{16}$ The appellant, a barrister registered in NSW, had applied for admission to practise in Queensland, and was refused on the basis of his lack of intention to practise principally in Queensland (shown by his continued domicile and practice in NSW). The Court unanimously found that the Bar Association of Queensland rules contravened s. 117; though the justification for this decision varied among the judges.

Each judge confirmed that the s. 117 test of discrimination required an analysis of how the affected individual was treated compared with a hypothetical person sharing all of their qualities except for interstate residence. Justice Deane noted that neither [of the] requirements [for admission] can properly be seen as flowing naturally from, or being a natural incident of, the privilege of practising as a barrister in Queensland in the sense of being a necessary professional qualification or safeguard. ${ }^{17}$

and, therefore, interstate applicants were subject to discrimination under the section. Pertinently, Justice Brennan concluded that

[this] law ... opens too the doors of state universities, hospitals and other institutions for entry by subjects of the

Queen resident in other states on the same terms as residents of the relevant state. ${ }^{18}$

As s. 117 was not intended to remove all state autonomy, there will be some circumstances in which the discrimination is justified if it is reasonably appropriate and adapted to the attainment of some legitimate objective. ${ }^{19}$ However, arguments that interstate lawyers would lack familiarity with local rules, or would be unable to perform their professional duties as satisfactorily as resident lawyers, have been consistently rejected due to lack of evidence. ${ }^{20}$

\section{Legal analysis}

Those defending the priority system might argue that the system discriminates on the basis of the location of the

\section{Variation in definitions of intern priority 1 groups}

State

\section{Priority 1 definition}

\begin{tabular}{|c|c|}
\hline Victoria & Group 1: Australian permanent resident graduates of Victorian universities (including domestic full-fee graduates and New Zealand citizens) ${ }^{2}$ \\
\hline Queensland & Priority category 1: Medical graduates of Queensland universities who are Australian citizens, Australian permanent residents or New Zealand citizens' \\
\hline New South Wales* & $\begin{array}{l}\text { Category 1.1: Commonwealth-supported place (CSP) and domestic full-fee graduates of a NSW university } \\
\text { Category 1.2: CSP and domestic full-fee graduates of an interstate or New Zealand university who completed year } 12 \text { in NSW } \\
\text { Category 1.3: CSP and domestic full-fee graduates of interstate or New Zealand universities }\end{array}$ \\
\hline Tasmania & Australian citizens or permanent resident [CSP] graduates of the University of Tasmania ${ }^{3}$ \\
\hline Western Australia & Priority category 1: all graduates of WA medical schools who are Australian citizens or permanent residents or New Zealand citizens ${ }^{4}$ \\
\hline South Australia ${ }^{\dagger}$ & $\begin{array}{l}\text { 1. CSP and SA Bonded Medical Scholarship Scheme graduates from an SA university who are Australian citizens or permanent residents or New } \\
\text { Zealand citizens } \\
\text { 1.1. CSP or domestic full-fee graduates of an Australian or New Zealand university outside SA who completed year } 12 \text { in SA and who are Australian } \\
\text { citizens or permanent residents or New Zealand citizens } \\
\text { 1.2. Domestic full-fee graduates of an SA university who are Australian citizens or permanent residents or New Zealand citizens }\end{array}$ \\
\hline
\end{tabular}

* Currently only Category 1.1 are guaranteed positions in NSW. ${ }^{5}+$ Group 1 (not groups 1.1 or 1.2) are guaranteed a position in South Australia. ${ }^{6}$ 


\begin{tabular}{|c|c|c|}
\hline State & Allocation methodology & Further details \\
\hline New South Wales & Computer algorithm & Allocated to hospitals by a program maximising preferences of the group via optimised preference matching \\
\hline Victoria & Merit & Selection by hospitals, eg, using curriculum vitae (CV), group or individual interviews, referee reports \\
\hline Queensland & Computer ballot & Some randomly selected applicants to oversubscribed hospitals are allocated to undersubscribed hospitals \\
\hline South Australia & Computer ballot & Some randomly selected applicants to oversubscribed hospitals are allocated to undersubscribed hospitals \\
\hline Western Australia & Merit & $\begin{array}{l}\text { Applicants provide written answers to set questions regarding: } \\
\text { ability to work effectively in a health care environment } \\
\text { commitment to working in WA } \\
\text { commitment to continued learning }\end{array}$ \\
\hline Tasmania & Merit & Selection by hospitals based on CV, interview and referee reports \\
\hline Northern Territory & Merit & $\begin{array}{l}\text { Selection by hospitals after centralised application process; informal preference given to Flinders University } \\
\text { graduates and others who completed rotations and electives in the NT }\end{array}$ \\
\hline Australian Capital Territory & Merit & ANU graduates are the highest priority, remaining positions are filled on merit as determined by CV and intervi \\
\hline
\end{tabular}

* Details were checked with relevant state and territory authorities.

student's medical school rather than state of residence and that s. 117 does not apply; or, if s. 117 does apply, that a sufficient justification for the discrimination exists.

We doubt that the High Court would find the first argument compelling, as it would be almost impossible to undertake mandatory clinical rotations without living in the state in which medical training is being undertaken. Today's High Court would likely look at the substance of the underlying discrimination rather than the form of wording. In Street, Chief Justice Mason confirmed that an analysis of the effect of the relevant law is necessary to avoid depriving s. 117 of practical effect, observing that

a disability or discrimination based upon grounds apart from residence is effectively removed if those grounds relate to characteristics which are ... concomitants of the individual's notionally changed residence. ${ }^{21}$

Our view is that the modern test reveals what the discrimination is truly based on: the state of the applicant's residence, which is a necessary concomitant of location of their medical school.

Supporting this conclusion, in a subsequent case concerning size of a state insurance payout to an individual, the High Court held unanimously that a clause designed to limit damages for an interstate resident but not for an "in-state" resident was invalidated by s. $117 .^{22}$ Chief Justice Mason also noted in Street that "s. 117 is not susceptible of 'colourable evasion' by state legislatures" who may seek to hide discriminatory practices under creative legal drafting. ${ }^{23}$

In Sweedman $v$ TAC, although the Gleeson High Court did not consider it an infringement to discriminate on the basis of the state a car was garaged in for the purposes of determining compensation recovery of the Victorian Transport Accident Commission, this interpretation primarily turned on payment of a transport accident charge rather than on residential location itself. ${ }^{24}$ There was no differential treatment on the basis of residence that would infringe s. 117, as a vehicle could be registered (and the relevant charge paid) in a state irrespective of whether its owner resides there. In contrast, the residence of a person while in medical school is intrinsically related to their enrolment at a medical school; one cannot simply submit an interstate address for the purpose of internship applications to "cure" the discrimination arising from the priority system.
The modern High Court's unsympathetic attitude to state protectionism was demonstrated in a case invoking s.92 of the Constitution involving free movement of goods and commerce between states, in which the High Court found unconstitutional Western Australian attempts to prevent a Tasmanian-based internet gambling exchange from operating in Western Australia. ${ }^{25}$ The unanimous decision deemphasised geographical boundaries, with Justice Heydon noting that part of the legislation was designed to create "a smokescreen" ${ }^{26}$ The case is particularly relevant given Chief Justice Mason's observation in Street that s. 117 was intended to operate as "a counterpart" to other constitutional provisions, including s. $92 .^{27}$

The argument regarding sufficient justification for the discrimination is more uncertain. We wrote to the federal and state health ministers, drawing attention to s. 117 and explaining the conflict, inviting them to provide a rationale or justification for the priority system. Most ministers provided general information regarding the priority system, or its historical genesis from the 2006 Council of Australian Governments meeting in which health ministers undertook to guarantee sufficient internship places for Australian citizens in Commonwealth-supported places at Australian medical schools. ${ }^{28}$ These responses did not provide specific information which could be readily evaluated against the types of justifications the High Court has previously considered. Two ministers asserted their belief in the legality of the scheme. One minister stated that as an internship is considered the final year of training of a medical degree, the [state] government believes that prioritising places for [state] graduates in their final year of learning in [state] provides a continuum of learning for those who have studied in [state].

If this rationale were argued before the High Court, we doubt it would be accepted. Students in Australia graduate from medical school before they become interns. Interns are paid a salary and given the title "doctor"; students are not. International medical graduates who complete their internship in Australia cannot continue on a student visa, and must obtain a temporary business visa. Moreover, even if internship were the final year of training for a medical degree, it seems an insufficient justification for discrimination that ranks interstate candidates unfavourably. There may be some benefit in continuity in working in the same state of medical schooling, but graduates moving interstate for internship would undertake the same core rotations in surgery, medicine 
and emergency medicine, and access the same nationally endorsed prevocational curriculum. ${ }^{29}$ Medical schools nationwide are all currently accredited by the Australian Medical Council to train medical students to the standard required to begin internship, so no state could credibly claim that its graduates were more appropriate than or superior to interstate graduates.

It could be argued that the priority system allows a state to better forecast and budget for intern positions, and plan for the health needs of their population. While an empirical analysis of this argument is not possible without more information, it is difficult to see how it would be compelling. Provisions such as ss. 117 and 92 were drafted to promote Australia's new federal structure by allowing the free movement of people and goods nationwide. As medical schools are not established with the intention of producing doctors purely for the benefit of the state they are in, and graduate numbers are disproportionate to internship places in certain states, the argument is bolstered that state-based discrimination in internship selection undermines national unity and infringes s. 117. If the priority system were removed, states would be free to employ the same number of interns as they do now, minimising budgetary impacts but allowing interns to move more freely, promoting national unity.

States might be able to show that such discrimination is proportionate and adapted to some other legitimate interest, but based on the replies we received from the health ministers and the blanket nature of discrimination in the priority system, we doubt that any justifications would withstand the High Court's scrutiny.

\section{Conclusions}

The departure from the principle of equality of citizens in competing for jobs promulgates more than mere academic concern. Erosion of rights may start with seemingly minor irregularities, tolerated on pragmatic grounds, before further changes increase the differences in treatment between citizens.

The recent changes to the priority system in Victoria are a predictable next step in this process, in which temporary residents (international students) graduating from Victorian medical campuses are now the second priority category. ${ }^{2}$ The outcome for Australian citizens is that any interstate applicant (including a Victorian secondary or undergraduate student who moved interstate to study medicine) is now in a lower priority category than every Victorian temporary resident, and has a greatly diminished chance of gaining an internship position in Victoria. As many universities wish to be attractive to international students, other states may be tempted to mimic Victoria's changes in order to remain competitive by offering a bolstered chance of internship to such students.

We argue that distinctions between intrastate and interstate applicants should be abolished; these applicants should be all considered of the highest and equal priority. Movement towards better coordination of intern recruitment, via the National Intern Allocation Working Party and a recently proposed online national intern allocation portal, ${ }^{30}$ could be used to promote wider reforms of the system. If this did not occur, litigation could be considered by individuals or groups, as a mechanism of achieving change. Any selection rules found to be unconstitutional would be void and therefore have no lawful effect. Some previous High Court cases upholding constitutional rights have led to the swift redirection of government resources. ${ }^{31}$

Acknowledgements: We thank Caitlin Farmer (Monash Medical Centre) for research assistance. We also thank Jeffrey Goldsworthy (Faculty of Law, Monash University), Leon Piterman (Faculty of Medicine, Monash University) and Simon Quinn (All Souls' College, Oxford University) for their helpful comments on manuscript drafts.

Competing interests: No relevant disclosures.

Disclaimer: The views and opinions expressed in this article are solely those of the authors and do not necessarily reflect the views of Austin Health.

Provenance: Not commissioned; externally peer reviewed.

Received 15 Jun 2012, accepted 20 Jan 2013

1 Queensland Health. Priority groups. Brisbane: Queensland Health, 2012. http:// www.health.qld.gov.au/medical/intern/priority-interns.asp (accessed Feb 2013).

2 Postgraduate Medical Council of Victoria. Intern match: priority groups. Melbourne: PMCV, 2012. http://computermatching.pmcv.com.au/public/howto/index.cfm (accessed Feb 2013).

3 Department of Health and Human Services. Intern recruitment processes. Hobart: DHHS, 2012. http://www.dhhs.tas.gov.au/career/home/medical/junior_docs/current campaign/campaigninterns (accessed May 2012).

4 Postgraduate Medical Council of Western Australia. http://www.pmcwa.health.wa. gov.au/faq/apps_process.cfm (accessed Dec 2012).

5 Health Education and Training Institute. NSW Health priority list for intern allocation 2013. Sydney: HETI, 2012. http://www.heti.nsw.gov.au/resources-library/nsw-healthpriority-list-intern-allocation-2013 (accessed Feb 2013).

6 South Australian Institute of Medical Education and Training. Priority groups. Adelaide: SA IMET, 2012. http://www.saimet.org.au/index.php/junior-doctors/interns/prioritygroups (accessed Feb 2013).

7 Elkin K, Studdert M. Restricted career paths for overseas students graduating from Australian medical schools: legal and policy considerations. Med J Aust 2010; 192: 517-519.

8 Australian Broadcasting Corporation News. Anger over medical internships. ABC News [internet] 2011; 30 Mar. http://www.abc.net.au/news/2011-03-30/anger-overmedical-internships/2637726 (accessed Feb 2013).

9 Kappagoda A. Training doctors - too long in the cellar? Med J Aust 2012; 196: 489

10 Health Workforce Australia. Health workforce 2025, volume 1: Doctors, nurses and midwives. Adelaide: HWA, 2012: 103. http://www.hwa.gov.au/health-workforce-2025 (accessed Feb 2013).

11 Australian Medical Association. Report highlights critical shortage of training positions for medical graduates. Canberra: AMA, 2012. http://ama.com.au/node/7741 (accessed Feb 2013).

12 Medical Deans Australia New Zealand. Medical student student statistics: snapshot data 2011-2012. Australian domestic graduates by state, 20062016. Sydney: MDANZ. http://www.medicaldeans.org.au/wp-content/ uploads/Online-Graphs-SNAPSHOT-graphs.pdf (accessed Feb 2013).

13 Royal College of Pathologists of Australasia. Pathology workforce - short version June 2010. Sydney: RCPA, 2010. http://www.rcpa.edu.au//static/File/ Asset\%20library/public\%20documents/Publications/Fact\%20Files/ PathologyWorkforceFactFile.pdf (accessed Feb 2013).

14 Royal Australasian College of Surgeons. Selection requirements and SET application. Melbourne: RACS, 2013. http://www.surgeons.org/becoming-a-surgeon/surgery-asa-career/selection-requirements (accessed Feb 2013).

15 Royal Australian and New Zealand College of Anaesthetists. Guidelines for the selection of trainees. Melbourne: RANZCA, 2012. http://www.anzca.edu.au/trainees/ registration/guidelines-for-the-selection-of-trainees (accessed May 2012).

16 Street v Queensland Bar Association (1989) 168CLR 461.

17 Street at 531

18 Street at 521

19 Street at 491-492.

20 Street at 493

21 Street at 489

22 Goryl v Greyhound (1994) 179 CLR 463.

23 Street at 489.

24 Sweedman v TAC (2006) 226 CLR 362 at 408-409.

25 Betfair Pty Ltd v Western Australia (2008) 234 CLR 418.

26 Betfair at 488.

27 Street at 485.

28 Council of Australian Governments Meeting, 14 July 2006, Communique. Canberra: COAG, 2006. http://archive.coag.gov.au/coag meeting_outcomes/2006-07-14/ index.cfm (accessed Feb 2013).

29 Confederation of Postgraduate Medical Education Councils. Background to the Australian curriculum framework for junior doctors. Melbourne: CPMEC, 2012. http://curriculum.cpmec.org.au/background.cfm (accessed Feb 2013).

30 Bonning MA, Fielke RJ, Mitchell RD. The case for a national intern allocation system in Australia. Med J Aust 2012; 197: 206-207.

31 Dietrich v The Queen (1992) 177CLR 292. 